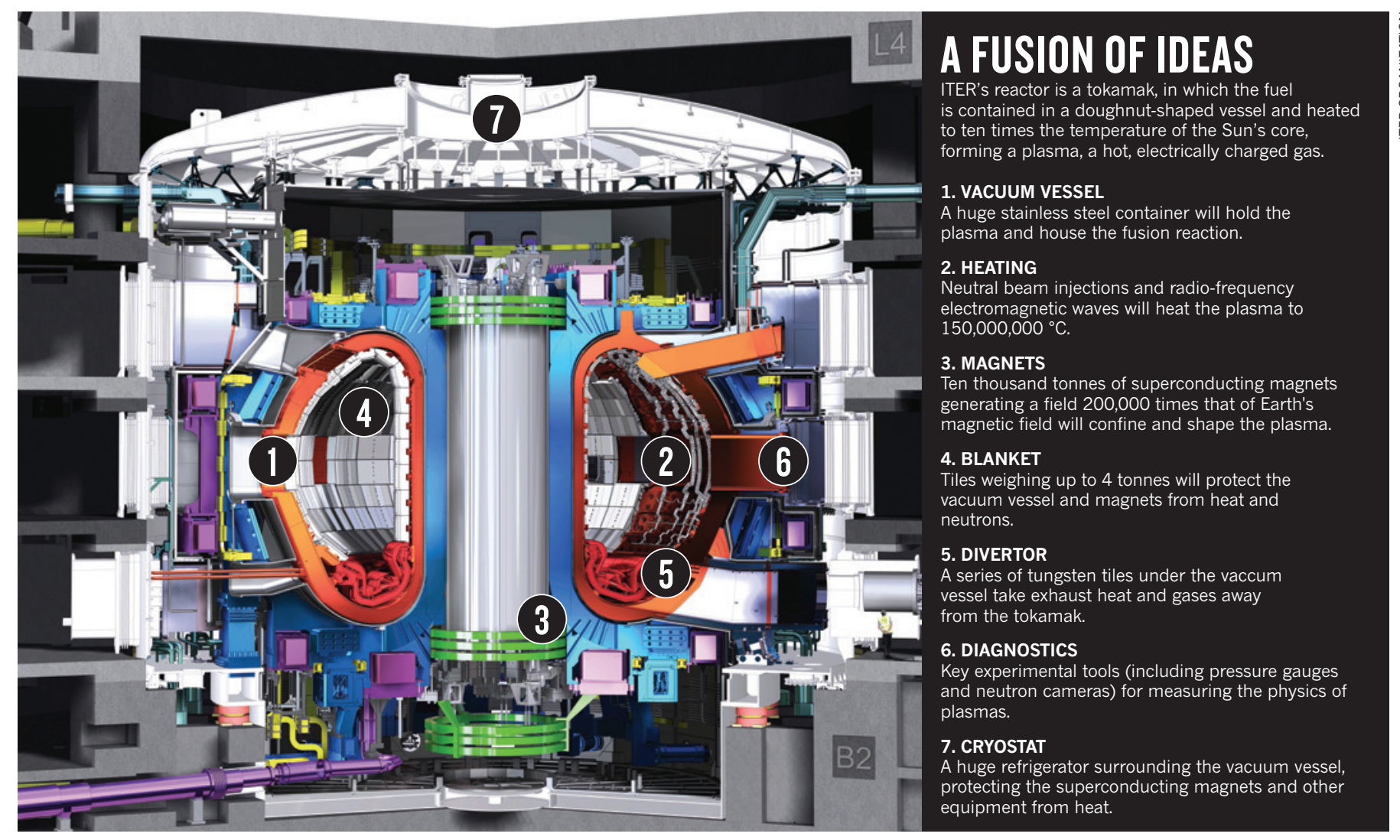

\title{
ITER keeps eye on prize
}

\section{Construction delays force rethink of research programme, but fusion target still on track.}

\section{BY DECLAN BUTLER}

$\mathrm{D}$ elays in the installation of key parts of ITER, a multibillion-euro international nuclear-fusion experiment, are forcing scientists to change ITER's research programme to focus exclusively on the key goal of generating power by 2028 . As a result, much research considered non-essential to the target, including some basic physics and studies of plasmas aimed at better understanding industrial-scale fusion, will be postponed.

Nature has learned that the plans form the main thrust of recommendations by a 21-strong expert panel of international plasma scientists and ITER staff, convened to reassess the project's research plan in the light of the construction delays. The plans were discussed this week at a meeting of ITER's Science and Technology Advisory Committee (STAC).

The meeting is the start of a year-long review by ITER to try to keep the experiment on track to generate $500 \mathrm{MW}$ of power from an input of 50 MW by 2028, and so hit its target of attaining the so-called $Q \geq 10$, where power output is ten times input or more.
ITER, which will be the world's largest tokamak thermonuclear reactor (see 'A fusion of ideas'), is being built in St-Paul-lez-Durance in southern France by the European Union, China, India, Japan, South Korea, Russia and the United States at a cost of $€ 15$ billion (US $\$ 20.3$ billion). $Q \geq 10$ is seen as its raison d'être, and achieving it would be likely to revitalize public and political interest in fusion. Crucial to that is getting to the point, scheduled for 2027, when the first nuclear fuel would be injected into the reactor. The fuel will be a plasma of two heavy hydrogen isotopes, deuterium and tritium (DT).

The original 2010 research plan foresaw the entire reactor being built by 2020 , when ITER was also scheduled to produce its first plasma, using hydrogen as a test fuel. But cost-cutting and cash-flow problems in member states mean that while the reactor is likely to be operating by then, the delivery of some parts is being deferred until several years later. These include some diagnostics devices for analysing the physics of plasmas at the very large scales of ITER, and elements of the heating system that will eventually take the plasmas to $150,000,000^{\circ} \mathrm{C}$.
"The plan was that everything would be procured and installed before first plasma, and then we would go straight into operation with a full set of systems," says David Campbell, head of ITER's plasma directorate. Instead, researchers will start with an initial set of instruments and systems, with others added later as upgrades. One of the main aims of the STAC meeting was for ITER to learn what elements of the research programme were essential to keeping it on track to reach DT phase and $Q \geq 10$ on schedule. A local plant that will produce tritium, for example, is one key element.

The outcome of the review is also expected to influence ITER member states' deferral plans, which will be modified to meet the key scientific priorities identified in the review. By fixing a timetable, Campbell says, STAC "will match up delivery schedules to the research plan, so that the research plan is not waiting for stuff to be delivered".

The likely consequence of capping costs is that some parts of the research plan will be postponed until after 2028. ITER initially aims to produce a $Q \geq 10$ for a few seconds, and then 
for pulses of 300-500 seconds, and work up over the following decade to output ratios of 30 times more power out than in, with pulses lasting almost an hour. Eventually the aim is to develop steady-state plasmas, which will yield information relevant to industrial-scale fusion-power generation. It is experiments relating to the understanding of longer-pulse and steady-state ITER plasmas that are most likely to be delayed beyond 2028 .

Research into better plasma performance, and with it greater energy output, may also be held back, along with experiments investigating how to control turbulence, which can damage the reactor wall, and the stability and energy characteristics of plasmas.

Olivier Sauter at the Swiss Federal Institute of Technology in Lausanne, Switzerland, one of the reviewers of ITER's research plan, says that months or more might be cut from the time needed to reach DT. But ITER's decision to take shortcuts also carries risks, he adds. To help mitigate these, ITER is working closely with researchers at other tokamaks around the world, such as the Joint European Torus in Oxfordshire, UK, to address some of the uncertainties likely to be encountered in plasma energies and stability.

"It is somewhat unfortunate that the compression of the ITER schedule will limit interesting research opportunities during the early stages of ITER operation, but the mission of ITER is clear," says Mickey Wade, director of the US national DIII-D fusion programme at General Atomics in San Diego, and a member of the review panel advising STAC. "The ITER physics team has done an admirable job of maintaining a single-minded focus on obtaining $Q \geq 10$ operation as early as possible." -

\section{UK push to open up patients' data}

\section{Government faces obstacles to mining medical records.}

\section{BY EWEN CALLAWAY}

$\mathrm{I}$ n August, posters began appearing in doctor's practices across England, urging patients to say yes to their medical records being used for scientific research - or, more precisely, not to say no.

The move, now gathering momentum, is part of a campaign by the UK government, alongside major research funders such as the Wellcome Trust in London, to convince a sceptical public to share their health details with researchers, through a system in which patients must expressly opt out. Privacy advocates are encouraging them to do just that.

The government's plans are part of a shakeup of health data in the National Health Service (NHS) in England, the world's largest $\approx$ public-health system, that cares for about 53 million people. Following reforms made in April, it will in the coming weeks begin radically changing the way it handles patients' records. This will involve establishing a central repository to connect hitherto disparate electronic data from general practitioners' (GP) practices, hospitals and disease registries.

Such linkage, already in place in Scotland and Wales, where the NHS is run separately, will deliver better health care, the government says, while establishing the world's most comprehensive patient database for research. It could be used to find new uses for existing drugs, and speed up the transfer of research to the clinic.

"The potential crown jewels in the UK are primary-care data that have been electronic for decades and have been coded for decades and have wide population coverage, nearly $100 \%$," says Harry Hemingway, director of the Farr
Health Informatics Research Institute at University College London, which was established this year with funding from the UK Medical Research Council to mine such records. Such an archive would trump those in the United States, and even in Denmark and Sweden, which have had central health databases for years.

The immediate use of the linked data will be to help the NHS apportion resources, but the government is also keen to make patients' records more useful - and accessible - to researchers in academia and industry. Prime Minister David Cameron has said that every NHS patient should be a research participant. His administration is also hoping that access to patients' data will lure drug companies back to Britain, and catalyse a health-informatics industry potentially worth billions of pounds.

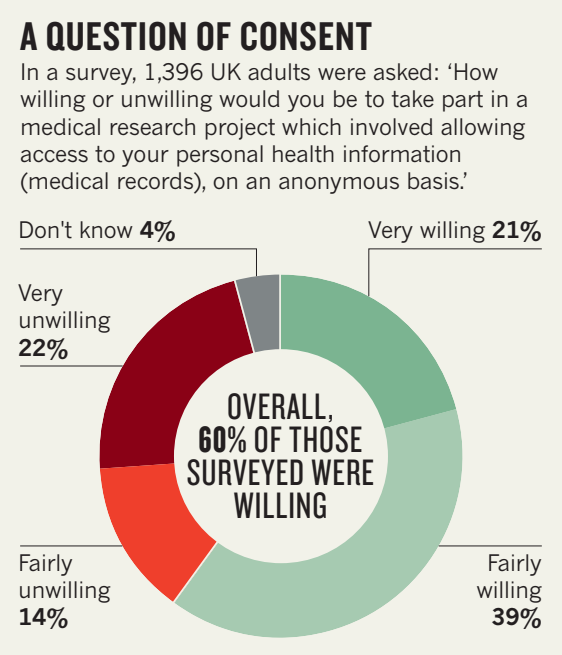

This autumn, GPs' records will begin migration to a data centre, where they will be linked with other data, including already-centralized hospital records. Some of this information - stripped of identifying details or fully anonymized - will also be made available to approved researchers through a secure portal.

According to some proponents of the plan, patients have little reason to opt out. "People think their records are being shared much more than they already are," says Nicola Perrin, head of policy at the Wellcome Trust, the UK's biggest funder of biomedical research. She worries that the public in England have not been adequately informed about the benefits of records sharing, such as improved health care, nor about measures intended to protect privacy. "I think there is underlying support for it, provided one can explain that there are safeguards, and that it isn't your most personal secrets that researchers want to get," she adds (see 'A question of consent').

Yet research funders worry that scaremongering in sections of the press could lead to large numbers of people opting out of the scheme, diluting its usefulness to researchers. In response, funders plan to become more vocal in touting the benefits of health-records research, such as very large epidemiological studies showing the effectiveness of smoking bans and the safety of vaccines. "When you explain that all of this research is only possible by using patient records, then people change their minds," says Janet Valentine, head of public health and ageing at the Medical Research Council, the UK's publicly funded agency for biomedical research, which spent $£ 760$ million (US $\$ 1.2$ billion) on research last year.

Phil Booth, head of a campaign called medConfidential that opposes the changes, worries that medical research is being used as a patient-friendly cover to collect data for other uses, such as the administration of social-security benefits. If privacy were compromised - an inevitability, Booth says - patients might lose faith in research and the NHS. His organization successfully fought for patients to be able to opt out. "I think research institutions are basically being rather short-sighted in aligning themselves with this initiative," he says. - 